\title{
Demonstration of a potent $R E T$ transcriptional inhibitor for the treatment of medullary thyroid carcinoma based on an ellipticine derivative
}

\author{
VISHNU MUTHURAJ KUMARASAMY ${ }^{1}$ and DAEKYU SUN ${ }^{1,2}$ \\ ${ }^{1}$ College of Pharmacy, and ${ }^{2}$ Arizona Cancer Center, University of Arizona, Tucson, AZ 85719, USA
}

Received March 6, 2017; Accepted April 28, 2017

DOI: 10.3892/ijo.2017.3994

\begin{abstract}
Dominant-activating mutations in the RET (rearranged during transfection) proto-oncogene, which encodes a receptor tyrosine kinase, is often associated with the development of medullary thyroid carcinoma (MTC). The proximal promoter region of the RET gene consists of a guanine-rich sequence containing five runs of three consecutive guanine residues that serve as the binding site for transcriptional factors. As we have recently shown, this stretch of nucleotides in the promoter region is highly dynamic in nature and tend to form non-B DNA secondary structures called $\mathrm{G}$-quadruplexes, which suppress the transcription of the $R E T$ gene. In the present study, ellipticine and its derivatives were identified as excellent RET G-quadruplex stabilizing agents. Circular dichroism (CD) spectroscopic studies revealed that the incorporation of a piperidine ring in an ellipticine derivative, NSC311153 improves its binding with the G-quadruplex structure and the stability induced by this compound is more potent than ellipticine. Furthermore, this compound also interfered with the transcriptional mechanism of the RET gene in an MTC derived cell line, TT cells and significantly decreased the endogenous RET protein expression. We demonstrated the specificity of NSC311153 by using papillary thyroid carcinoma (PTC) cells, the TPC1 cell line which lacks the G-quadruplex forming sequence in the promoter region due to chromosomal rearrangement. The RET downregulation selectively suppresses cell proliferation by inhibiting the intracellular Raf/MEK/ERK and PI3K/Akt/mTOR signaling pathways in the TT cells. In the present study, we also showed that the systemic administration of a water soluble NSC311153 analog in a mouse MTC xenograft model inhibited the tumor growth through RET downregulation.
\end{abstract}

Correspondence to: Dr Daekyu Sun, College of Pharmacy, University of Arizona, Tucson, AZ 85719, USA

E-mail: sun@pharmacy.arizona.edu

Key words: RET, medullary thyroid carcinoma, ellipticine, G-quadruplex

\section{Introduction}

The RET proto-oncogene, which is a key component in the development of enteric nervous system, encodes a transmembrane receptor-type tyrosine kinase $(1,2)$. The domain organization of the RET protein includes a ligand-binding extracellular domain, a transmembrane domain and an intracellular tyrosine kinase domain (3-5). The ligands for RET receptor have been identified as the members of glial cell line derived neurotrophic factor (GDNF) family that activate this protein through the interaction with glycosylphosphatidylinositol linked GFR- $\alpha$ co-receptors $(6,7)$. These co-receptors mediate RET homodimerization that leads to trans-autophosphorylation of the tyrosine residues present in the intracellular kinase domain thereby activating its function (8). Upon activation, the phosphorylated tyrosine residues act as binding sites for many adaptor molecules that trigger a cascade of intracellular signaling pathways (9). The major mitogenic signaling pathways include the Raf/MEK/ERK and $\mathrm{PI} 3 \mathrm{~K} / \mathrm{Akt} / \mathrm{mTOR}$ pathways that contribute to cell proliferation and survival (10-12).

Activating RET germline mutations have been identified as the key cause for the pathogenesis of medullary thyroid carcinoma (MTC), which is a part of multiple endocrine neoplasia type 2 (MEN2) syndrome $(13,14)$. Patients with MEN2 harbor several mutations in the RET protein that leads to ligand independent phosphorylation and activation of the receptor thereby resulting in the constitutive signaling of intracellular pathways $(15,16)$. Unlike other differentiated thyroid cancers such as papillary thyroid carcinoma (PTC) and follicular thyroid carcinoma (FTC), MTC is poorly-differentiated and hence it metastasizes rapidly to distant organs like bones, lungs and liver $(17,18)$. Moreover, most MTC patients have tumor invasion at the time of diagnosis that hampers the effectiveness of standard therapies such as surgical resection of the thyroid gland and external beam radiation (18). Hence, a systemic targeted therapy has gained considerable clinical interest for the treatment of advanced and progressive MTC (19). Owing to the oncogenic potential of RET in the development of MTC, it has been regarded as an ideal molecular target for therapeutic intervention $(19,20)$. Although several approaches have been developed including the use of kinase inhibitors and small interfering RNA (siRNA) to abrogate the RET kinase 
<smiles>Cc1c2cnccc2c(C)c2c1[nH]c1ccccc12</smiles>

NSC155694<smiles>COc1ccc2c(c1)c1c(C)c3c[n+](C)ccc3c(C)c1n2C</smiles>

NSC311152

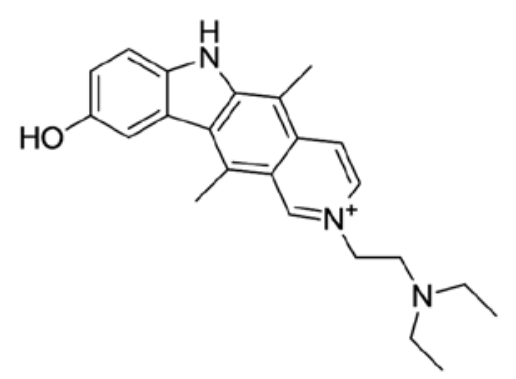

2-Hydroxycarbazole<smiles>Oc1ccc2c(c1)[nH]c1ccccc12</smiles>

NSC632855<smiles>Cc1c2cc[n+](C)cc2c(C)c2c1[nH]c1ccc(Cl)cc12</smiles><smiles>COc1ccc2[nH]c3c(C)c4cc[n+](C)cc4c(C)c3c2c1</smiles>

NSC639364<smiles>Cc1ccc2[nH]c3c(C)c4cc[n+](C)cc4c(C)c3c2c1</smiles>

NSC311153<smiles>Cc1c2cc[n+](CCN3CCCCC3)cc2c(C)c2c1[nH]c1ccc(O)cc12</smiles>

Figure 1. Ellipticine analogs. Chemical structures of ellipticine and its derivatives.

activity and its expression, developing a specific RET inhibitor still remains challenging (20-22). Our previous study clearly showed that the transcriptional inhibition of the RET gene by targeting its promoter region could be a promising strategy for MTC specific therapy $(23,24)$.

The transcriptional activation of the $R E T$ gene is regulated by the presence of polypurine (guanine) and polypyrimidine (cytosine) tract in the proximal promoter region $(25,26)$. This upstream core promoter region serves as the binding site for RNA Pol II, Sp1 and other transcriptional factors that are responsible for the basal promoter activity (27). Our previous studies have clearly demonstrated that the G-rich sequences present within the RET promoter region are highly dynamic in nature, adopting non-B-DNA conformations such as G-quadruplex structures under negative supercoiling conditions (28-30). These secondary structures are four-stranded intramolecular folding of a single-stranded DNA, which is formed by the stacking of two or more G-tetrads (31). Each G-tetrad comprises of four guanines that are arranged in a square planar conformation and are interconnected through Hoogsteen hydrogen bonding $(31,32)$. The G-quadruplex structure on the promoter region is believed to serve as a silencer element for the RET transcription through the sequestration of the transcriptional factor binding sites (23). In our previous study, we have clearly demonstrated that the stabilization of the G-quadruplex structure formed on the RET promoter region by a small-molecule, berberine interfered with the binding of
SP1 and RNA Pol II thereby silencing the transcription of this gene $(23,24)$.

In continuation of our previous study, the main objective of the present study was to discover new drug-like small-molecules that have clinical implications as a potent suppressor of RET gene through the stabilization of the promoter G-quadruplex structure. Hence, we repurposed ellipticine and its structural derivatives as potential G-quadruplex stabilizing agents and also exerting transcriptional inhibitory effect on the RET gene in medullary thyroid carcinoma (MTC) derived TT cell line. Ellipticine is a natural alkaloid, which has been demonstrated to have therapeutic benefits in different types of cancers $(33,34)$. The anti-neoplastic activity of this molecule has been attributed to its ability to intercalate with DNA and/or to inhibit the topoisomerase II activity $(35,36)$. However, recent studies have revealed that ellipticine also binds and stabilizes the G-quadruplex structures formed on the telomere region and the promoter region of $c-M y c$ oncogene in vivo $(37,38)$. In order to identify promising lead compounds for the present study, we explored for different structural derivatives of ellipticine from the NCI/DTP open chemical repository (Fig. 1). This led us to the identification of NSC311153 and NSC311152 as lead compounds that silence the RET gene expression by targeting the G-quadruplex structure formed on the promoter region of this gene. We also investigated the cellular effects mediated by these compounds in TT cells and its in vivo antitumor efficacy using MTC xenograft models to further 
understand the therapeutic implications in targeting the $R E T$ transcription through the promoter G-quadruplex.

\section{Materials and methods}

Chemicals. Ellipticine was obtained from Santa Cruz Biotechnology (SC-200878; Santa Cruz, CA, USA). NSC311153 and other structural analogs were kindly provided from the U.S. NCI/DTP Open Chemical Repository. All the compounds were dissolved in dimethyl sulfoxide (DMSO) at a final concentration of $10 \mathrm{mg} / \mathrm{ml}$.

Materials. The 5'-FAM labelled RET-WT (5'-AGCGGGT AGGGGCGGGGCGGGGCGGGGGCGG-3') oligonucleotide was purchased from Sigma Genosys (Woodlands, TX, USA). Taq DNA polymerase was purchased from Fermentas (Hanover, MD, USA).

Cell culture and media. The TT cell line was obtained from the American Type Culture Collection (ATCC; Manassas, VA, USA) and maintained in Dulbecco's modified Eagle's medium (DMEM)/F-12 medium (Cellgro, Manassas, VA, USA) supplemented with $15 \%$ heat inactivated fetal bovine serum (FBS). The TPC1 cells and another MTC derived cell line, MZ-CRC-1 cells were provided by Dr Rebecca Schweppe (University of Colorado, Denver, CO, USA). These cells were maintained in RPMI-1640 medium supplemented with 9\% FBS and DMEM/F-12 medium supplemented with 15\% FBS, respectively. The isogenic cell line HEK293-RET, which carries the luciferase reporter gene under the control of $R E T$ gene promoter was generated as described in our previous study and grown in DMEM medium supplemented with 9\% FBS (23). The normal thyroid cell line, Nthy-ori-3-1 was purchased from Sigma Genosys and cultured in RPMI-1640 medium supplemented with $9 \%$ FBS. All the cell lines were maintained in a humidified atmosphere containing $5 \% \mathrm{CO}_{2}$ at $37^{\circ} \mathrm{C}$. The stocks for all these cell lines were obtained from the cell bank and utilized within 6 months. These cell lines were also tested for mycoplasma contamination and were further authenticated using STR profiling.

CD spectroscopy. The RET-WT oligonucleotide $(5 \mu \mathrm{M})$ was allowed to form the G-quadruplex structure in the presence of Tris- $\mathrm{HCl}$ buffer $(20 \mathrm{mM}, \mathrm{pH} 7.6)$ and $25 \mathrm{mM}$ $\mathrm{KCl}$ by denaturing at $95^{\circ} \mathrm{C}$ for $5 \mathrm{~min}$ and slowly cooled to room temperature. The $\mathrm{CD}$ spectra were recorded using a Jasco J-810 spectrophotometer (Jasco, Inc., Easton, MD, USA) using a quartz cell of $1 \mathrm{~mm}$ path length and instrument scanning speed of $100 \mathrm{~nm} / \mathrm{min}$ with a response time of $1 \mathrm{sec}$ over a wavelength range of 230-330 $\mathrm{nm}$ as previously described (23). The $\mathrm{T}_{\mathrm{m}}$ was determined by monitoring the molar ellipticity vs. temperature profiles at $262 \mathrm{~nm}$ at increasing temperature from 20 to $90^{\circ} \mathrm{C}$ at a gradient of $1^{\circ} \mathrm{C} / \mathrm{min}$.

Polymerase stop assay. The polymerase stop assay was performed on a DNA template containing the G-quadruplex forming sequence, which is present in the RET promoter region as previously described (39). In brief, the template DNA was annealed with a $5^{\prime}-\gamma\left[{ }^{32} \mathrm{P}\right]$ end-labelled primer (P28) and purified on an $8 \%$ non-denaturing polyacrylamide gel. The purified primer-DNA template was used in a primer extension assay in the presence of Taq DNA polymerase.

Dimethyl sulfate (DMS) footprinting. The DMS footprinting was performed on the 5'FAM labelled RET-WT oligonucleotides as described in our previous studies $(23,24)$. In brief, the oligonucleotides were allowed to form the G-quadruplex structure and were incubated in the absence and presence of NSC311153 (5 equivalents) at room temperature for $1 \mathrm{~h}$. The samples were treated with DMS $(0.2 \%)$ for 2 min and were resolved on an $8 \%$ non-denaturing polyacrylamide gel. Each DNA band was recovered from the gel and treated with piperidine $(10 \%)$ after ethanol precipitation. The cleaved products were resolved on a $16 \%$ denaturing polyacrylamide gel along with purine and pyrimidine specific sequencing markers that were generated according to the published procedure (40). The gel was dried and the fluorescence was read on a Typhoon 8600 scanner (GE Healthcare Life Sciences, Pittsburgh, PA, USA) for analysis.

Semi-quantitative RT-PCR analysis. Total RNA was extracted from the cells using the RNeasy Mini QIAcube kit (Qiagen, Redwood City, CA, USA) according to the manufacturer's protocol. The extracted RNA was subjected to reverse-transcription using the oligo (dT)18 primer with QuantiTect reverse-transcription kit (Qiagen) to generate single-stranded cDNA. The primers used for RT-PCR were as follows: RET forward, (5'-GCAGCATTGTTGGGGGACA-3') and RET reverse, (5'-CACCGGAAGAGGAGTAGCTG-3'); Rp19 forward, (5'-CTGAAGGGACGCACAGTTAT-3') and Rp19 reverse, (5'-ACGGTAGCCAGTTCCTTTCT-3'). The PCR reactions involved an initial denaturation at $95^{\circ} \mathrm{C}$ for $3 \mathrm{~min}$ followed by 33 and 23 cycles for RET and Rp19, respectively, at $95^{\circ} \mathrm{C}$ for $30 \mathrm{sec}, 52^{\circ} \mathrm{C}$ for $30 \mathrm{sec}$ and $72^{\circ} \mathrm{C}$ for $30 \mathrm{sec}$ on a GeneAmp PCR system 9600 (Perkin-Elmer, Waltham, MA, USA). The PCR products were analyzed on $1.5 \%$ agarose gel electrophoresis.

Western blotting. The whole-cell protein extracts were prepared by lysing the cells with $2 \%$ CHAPS lysis buffer in the presence of $10 \mathrm{mM}$ Tris- $\mathrm{HCl}, \mathrm{pH} 7.4,0.15 \mathrm{M} \mathrm{NaCl}, 5 \mathrm{mM}$ EDTA and Halt Protease Inhibitor Cocktail (Thermo Fisher Scientific, Waltham, MA, USA). The extracted proteins were resolved on a $4-12 \%$ polyacrylamide SDS-PAGE, as previously described $(23,24)$. The primary antibodies used were as follows: anti-RET (\#3220), anti-RET/PTC1 (\#14698), anti-cMYC (\#5605), anti-p-mTOR (\#2971) and anti-mTOR (\#2972) (dilution 1:1,000) were purchased from Cell Signaling Technology (Beverly, MA, USA), anti-Bcl-2 (sc-7382), anti-pERK (sc-7383), anti-ERK (sc-271270), anti-cyclin D1 (sc-20044) and anti- $\beta$-actin (sc-47778) (dilution 1:300) were purchased from Santa Cruz Biotechnology. Anti-VEGF antibody was purchased from GeneTex (Irvine, CA, USA; \#GTX102643). Mouse and rabbit IgG antibodies tagged with horseradish peroxidase (HRP) (Bio-Rad Laboratories, Hercules, CA, USA) were used as secondary antibodies (dilution 1:1,000). An enhanced chemiluminescence substrate kit (\#32106) purchased from Thermo Fischer Scientific was used for detection. 
Luciferase assay. The isogenic cell line HEK293-RET was exposed to different concentrations of NSC311153 up to $24 \mathrm{~h}$. Luciferase expression level is determined using the ONE-Glo Luciferase Assay system (Promega, Madison, WI, USA) following the manufacturer's instruction.

Cell viability assay. Cells were plated at a concentration of 7,500 cells/well in a 96-well dish and incubated overnight, followed by the treatment with NSC311153 at increasing concentrations up to $96 \mathrm{~h}$. The cell viability was determined by using $0.33 \mathrm{mg} / \mathrm{ml}$ MTS dye in the presence of phenazine methosulfate (PMS) $(25 \mu \mathrm{M})$ as previously described (41). The absorbance was measured at $590 \mathrm{~nm}$ using a Synergy HT multi-detection microplate reader (BioTek Instruments, Inc., Winooski, VT, USA).

Caspase-3 assay. TT cells were treated with different concentrations of NSC311153 up to $48 \mathrm{~h}$ and caspase-3 activity was measured using the ApoAlert Caspase Fluorescent Assay kit (Clontech Laboratories, Inc., Mountain View, CA, USA) by following the manufacturer's protocol.

In vivo studies. The in vivo antitumor efficacy of the ellipticine derivative was evaluated using 8-10-week old male severe combined immunodeficiency (SCID) mice, xenotransplanted with MTC derived TT cells. Animal experiments were conducted in accordance with the Institutional Animal Care and Use Committee (IACUC). The experiments were performed in the Experimental Mouse Shared Resource (EMSR) Animal Facility Laboratory (University of Arizona), which is accredited by the International Association for Assessment and Accreditation of Laboratory Animal Care (AAALAC). In brief, exponentially growing TT cells $\left(1 \times 10^{7}\right)$ were subcutaneously injected into the flank of the mice and the tumor growth was monitored every week by measuring the tumor diameters using a vernier caliper. Tumor volume was calculated according to the formula $\left(b^{2} \mathrm{xl}\right) / 2$ where $b$ and 1 are the shortest and the longest diameters, respectively. Once the tumor volume reaches $100 \mathrm{~mm}^{3}$, the mice are randomly pair matched to vehicle and treated group ( $n=8 /$ group). The compound was dissolved in $90 \%$ phosphate-buffered saline (PBS) and 10\% DMSO and administered intraperitoneally (i.p) at a single dose of $4 \mathrm{mg} / \mathrm{kg}$ for 5 days/week up to 2 weeks. The antitumor efficacy was assessed based on the percentage inhibition of tumor growth in treated vs. control group. The toxicity of the compound was evaluated based on the loss of average weight of mice. Tumor tissue from vehicle and treated group were explanted at the end of last dosage to examine the effect of the compound on the expression of proteins that contribute to tumor growth.

\section{Results}

Interaction of ellipticine with RET G-quadruplex. The molecular structure of ellipticine consists of an aromatic pyridocarbazole ring, which allows the $\pi-\pi$ stacking interactions with the planar guanine residues present in the terminal G-tetrad (Fig. 1) (37). Not surprisingly, previous studies have reported that ellipticine stabilizes different G-quadruplex structures formed on the telomere region and on the promoter region of $c-M y c$ oncogene $(37,38)$. Hence, in the present study we investigated whether this compound binds and stabilizes the RET G-quadruplex structure using CD spectroscopic analysis. First, we examined whether ellipticine alters the structural conformation of the RET G-quadruplex by monitoring the CD spectra of RET G4 sequence $(5 \mu \mathrm{M})$ in the absence and presence of increasing concentrations of this compound. As shown in Fig. 2A, the positive peak at $262 \mathrm{~nm}$, which corresponds to a parallel G-quadruplex structure (42), was not affected in the presence of ellipticine, suggesting that the parallel configuration of the RET G-quadruplex was not changed in the presence of this molecule. Next, we examined the thermal stability of the G-quadruplex structure by monitoring the CD melting curve in the absence and presence of ellipticine (1 equivalent) at increasing temperatures. As shown in Fig. 2B, the melting temperature $\left(\mathrm{T}_{\mathrm{m}}\right)$ of the RET G-quadruplex structure in the absence of ellipticine was determined to be $75^{\circ} \mathrm{C}$. Based on the melting curves, the binding of ellipticine with the G-quadruplex structure increases its melting temperature up to $85^{\circ} \mathrm{C}$ and the $\Delta \mathrm{T}_{\mathrm{m}}$ was found to be $10^{\circ} \mathrm{C}$ (Fig. 2B). To further understand the structural features required for the interaction of ellipticine with the RET G-quadruplex structure, we examined the binding of 2-hydroxycarbazole with this structure by monitoring the $\mathrm{CD}$ melting profiles. As shown in Fig. $2 \mathrm{C}$ the $\mathrm{T}_{\mathrm{m}}$ of the G-quadruplex structure was not increased even in the presence of 5 equivalents of 2-hydroxycarbazole, suggesting that the presence of pyridine ring in ellipticine allows additional $\pi-\pi$ interactions with the guanine residue. Overall these data imply that the pyridocarbazole ring moiety is essential for the stabilization of the RET G-quadruplex structure by ellipticine.

Effect of ellipticine on the RET expression. In our previous studies we have clearly demonstrated that the small-molecule mediated stabilization of the G-quadruplex structure formed on the RET promoter region exerts transcriptional inhibitory effect on this gene $(23,24)$. Hence, we determined whether ellipticine downregulates the endogenous RET expression in the TT cell line in which the RET gene transcription is regulated by the promoter region that contains the G-quadruplex forming sequence. As shown in Fig. 2D, a concentration dependent decrease in the RET protein expression was observed in the presence of ellipticine following 48-h exposure. To further confirm that the RET downregulation by ellipticine is mediated through the stabilization of the G-quadruplex structure, we determined the effect of 2-hydroxycarbazole on the RET expression in this cell line. As shown in Fig. 2E the RET protein expression was not decreased in the presence of this compound even at high concentration $(5 \mu \mathrm{g} / \mathrm{ml})$. These data are consistent with our previous studies that the stabilization of the G-quadruplex structure formed within the RET promoter region is responsible for silencing the expression of this gene.

Identification of NSC311153 as RET G-quadruplex binding compound. Although we identified ellipticine as a potent $R E T$ transcriptional inhibitor, this compound was withdrawn from this study due to its adverse cytotoxic effects in TT cells, which was evaluated by MTS assay. The $\mathrm{IC}_{50}$ of ellipticine was calculated to be $0.3 \mu \mathrm{g} / \mathrm{ml}$ after $96-\mathrm{h}$ treatment of TT cells in the presence of increasing concentration of this compound 


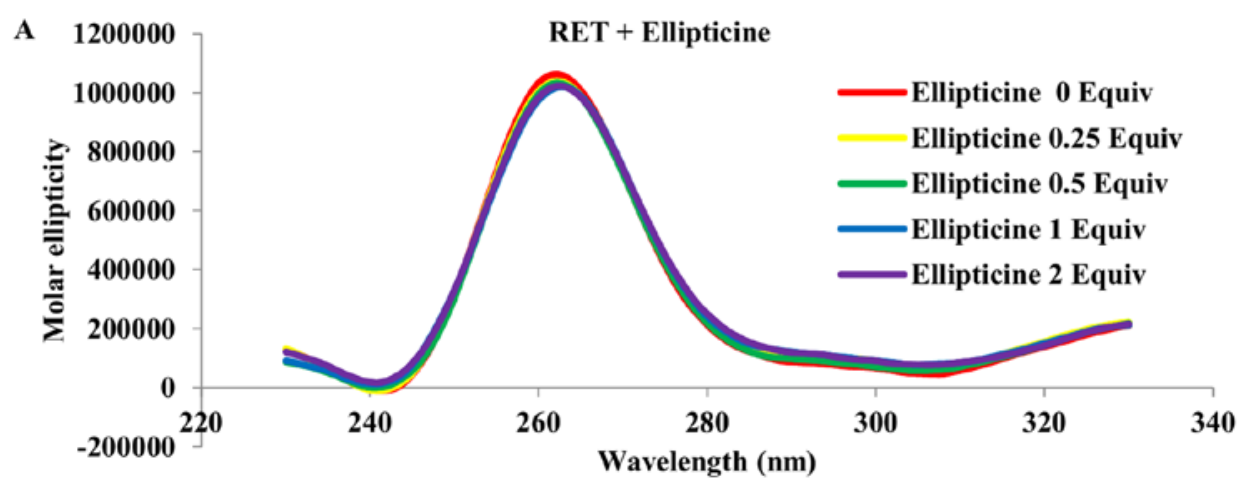

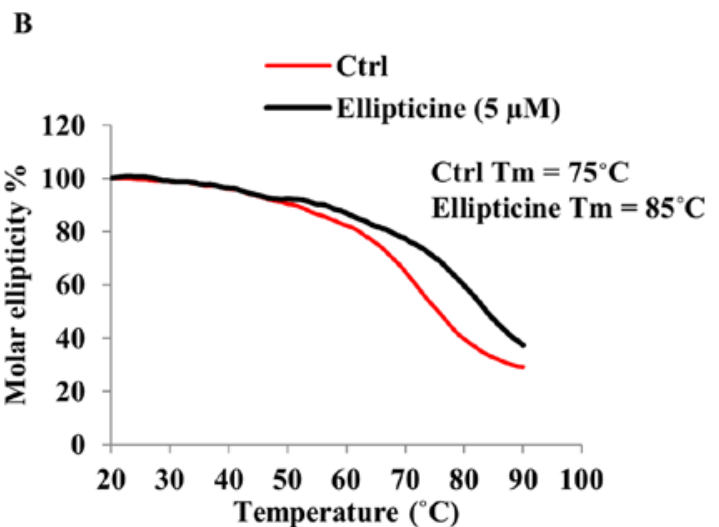

D

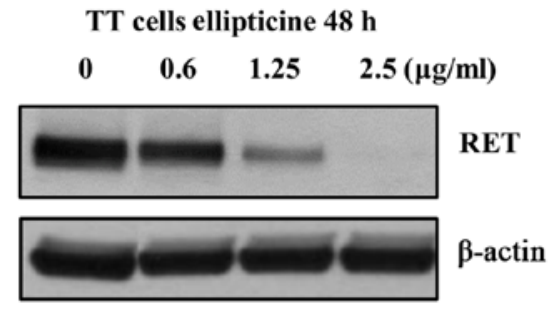

C

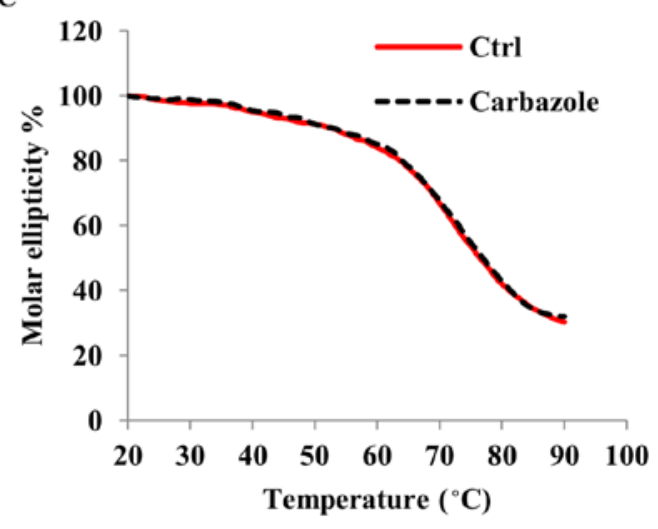

E

TT cells 2-hydroxycarbazole $48 \mathrm{~h}$

$\begin{array}{llll}0 & 1.25 & 2.5 & 5\end{array}(\mu \mathrm{g} / \mathrm{ml})$

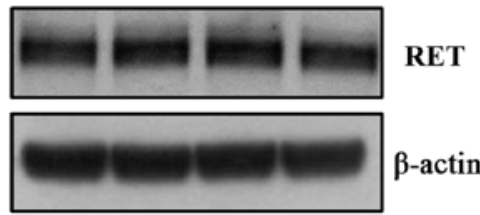

Figure 2. Evaluation of ellipticine as a potential RET G-quadruplex stabilizing agent. (A) CD titration spectra for the RET-WT (5 $\mu \mathrm{M})$ in the absence and presence of increasing concentrations of ellipticine. $x$-axes and $y$-axes represent the wavelength of the spectral scan and molar ellipticity of the G-quadruplex structure, respectively. (B) Melting curve of the RET-WT G-quadruplex in the absence and presence of ellipticine (1 equivalent). (C) Melting curve of the RET-WT G-quadruplex in the absence and in the presence of 2-hydroxycarbazole (5 equivalents). x-axes and y-axes represent the temperature and relative molar ellipticity of the G-quadruplex structure, respectively. (D) Western blot analysis to determine the effect of ellipticine on RET protein expression in TT cells after 48-h incubation. (E) Effect of 2-hydroxycarbazole on RET expression in TT cells at various concentrations.

(Fig. 3A). Hence, we attempted to identify other structural analogs of ellipticine from the NCI/DPT open chemicals repository that could suppress the $R E T$ gene transcription at non-toxic concentrations without affecting their ability to stabilize the RET G-quadruplex structure (Figs. 1 and 3A). Based on the CD melting curves the $\Delta \mathrm{T}_{\mathrm{m}}$ was calculated individually for the ellipticine analogs and the $\mathrm{IC}_{50}$ values for these compounds were also determined by MTS assay (Fig. 3A). The ellipticine derivatives, which have different substituents such as methoxy, chloride and methyl groups at position C-9 of the pyridocarbazole ring stabilizes the RET G-quadruplex structure by increasing the $\mathrm{T}_{\mathrm{m}}>10^{\circ} \mathrm{C}$ (Fig. 3A). These compounds also possess RET inhibitory effects in TT cells, which is comparable to their parent molecule, ellipticine (Fig. 3B). However, the structural modifications in these compounds did not improve the cytotoxicity in TT cells as compared to ellipticine (Fig. 3A). Notably, one of the ellipticine analogs, NSC311153, which carries a hydroxyl group and a 2-piperidin-1-ylethy moiety at positions C-9 and $\mathrm{N}-2$, respectively showed an increased binding ability with the RET G-quadruplex structure with an estimated $\Delta \mathrm{T}_{\mathrm{m}}$ as $15^{\circ} \mathrm{C}$ (Fig. 3A). The $\mathrm{IC}_{50}$ value of this compound was also estimated to be $2.5 \mu \mathrm{g} / \mathrm{ml}$ after $96 \mathrm{~h}$ of exposure, which is significantly higher than that of ellipticine (Fig. 3A). Based on these data, we selected NSC 311153 as a lead compound to further proceed with the in vitro studies.

Validation of NSC311153 as RET G4 stabilizing agent. To further validate that NSC311153 stabilizes the RET G-quadruplex structure formed on the promoter region of this gene, a DNA polymerase stop assay was performed as previously described (23). In this assay, the ligand mediated 
A

Cellular Toxicity \& $\Delta \mathrm{T}_{\mathrm{m}}$ of ellipticine analogs as determined by MTS assay and CD spectroscopy respectively<smiles>[R9]c1ccc2c(c1)c1c(C)c3c[n+]([R6])ccc3c(C)c1n2[R6]</smiles>

\begin{tabular}{|c|c|c|c|c|c|}
\hline Compounds & $\mathbf{R} 2$ & R6 & R9 & $\begin{array}{l}\text { Cellular toxicity } \\
\mathrm{IC}_{50}(\mu \mathrm{g} / \mathrm{ml})\end{array}$ & $\begin{array}{l}\text { Melting temperature } \\
\left(\Delta \mathrm{T}_{\mathrm{m}}{ }^{\circ} \mathrm{C}\right)\end{array}$ \\
\hline Ellipticine & & $\mathrm{H}$ & $\mathrm{H}$ & 0.3 & 10 \\
\hline NSC155693 & $\mathrm{CH}_{3}$ & $\mathrm{H}$ & $\mathrm{OCH}_{3}$ & 0.8 & 11 \\
\hline NSC155694 & $\mathrm{CH}_{3}$ & $\mathrm{CH}_{3}$ & $\mathrm{OCH}_{3}$ & 0.5 & 12 \\
\hline NSC632855 & $\mathrm{CH}_{3}$ & $\mathrm{H}$ & $\mathrm{Cl}$ & 0.6 & 11 \\
\hline NSC639364 & $\mathrm{CH}_{3}$ & $\mathrm{H}$ & $\mathrm{CH}_{3}$ & 1.0 & 12 \\
\hline NSC311153 & & $\mathrm{H}$ & $\mathrm{OH}$ & 2.5 & 15 \\
\hline NSC311152 & & $\mathrm{H}$ & $\mathrm{OH}$ & 2.63 & 15 \\
\hline
\end{tabular}

B TT cells NSC155693 $48 \mathrm{~h}$

$\begin{array}{lllll}0 & 1.25 & 2.5 & 5 & (\mu \mathrm{g} / \mathrm{ml})\end{array}$

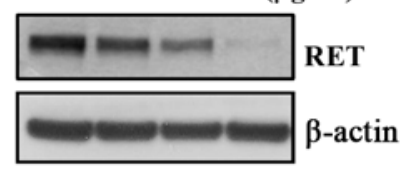

TT cells NSC639364 $48 \mathrm{~h}$

$\begin{array}{llll}0 & 1.25 & 2.5 & 5\end{array}(\mu \mathrm{g} / \mathrm{ml})$
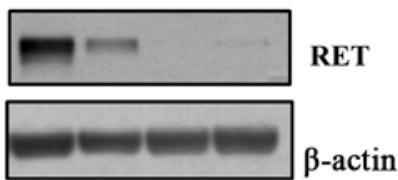

TT cells NSC155694 $48 \mathrm{~h}$

$\begin{array}{lllll}0 & 1.25 & 2.5 & 5 & (\mu \mathrm{g} / \mathrm{ml})\end{array}$

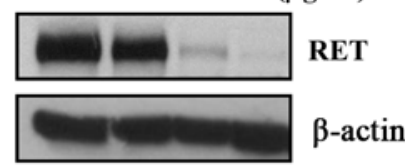

TT cells NSC311152 $48 \mathrm{~h}$

$\begin{array}{lllll}0 & 1.25 & 2.5 & 5 & (\mu \mathrm{g} / \mathrm{ml})\end{array}$

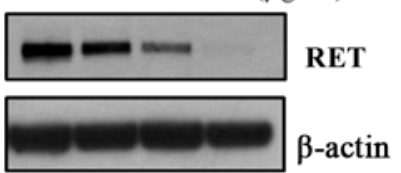

TT cells NSC632855 $48 \mathrm{~h}$

$\begin{array}{llll}0 & 1.25 & 2.5 & 5 \\ (\mu \mathrm{g} / \mathrm{ml})\end{array}$

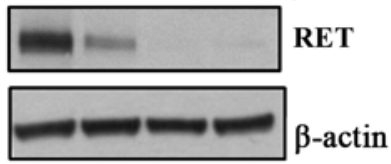

Figure 3. Effect of ellipticine and its structural derivatives on the RET expression in TT cells. (A) Ellipticine derivatives with different functional groups at positions $\mathrm{C}-9, \mathrm{~N}-2$ and $\mathrm{N}-6$. The $\mathrm{IC}_{50}$ values of the ellipticine derivatives in TT cells and the increase in G-quadruplex $\mathrm{T}_{\mathrm{m}}$ in the presence of these compounds were determined by MTS assay and CD spectroscopic analysis, respectively. (B) Evaluation of the RET inhibitory effects of all the ellipticine analogs in TT cells after 48-h treatment.

stabilization of the G-quadruplex structure that arises on the DNA template prevents the progression of the Taq DNA polymerase during primer extension. As shown in Fig. 4A, in the presence of NSC311153 at increasing concentrations, a dose-dependent increase in the amount of arrested product was observed, indicating the potential stabilization of the G-quadruplex structure by this compound.

Next, we investigated whether the interaction of NSC311153 with the parallel RET G-quadruplex structure changes the guanine residues that are involved in the G-tetrad formation using dimethyl sulfate (DMS) footprinting. DMS footprinting is a well-established technique to determine the guanine nucleotides that are involved in the formation of G-quadruplex structures $(40,43)$. The N7 position of each of the guanine residues that are involved in Hoogsteen base pairing to form G-tetrads is inaccessible to methylation by DMS, which attacks this position. As shown in Fig. 4B, the pattern of N7-guanine methylation produced by the RETG4 sequence in the presence of $100 \mathrm{mM} \mathrm{K}^{+}$is consistent with two parallel G-quadruplexes (lane C) in which either the guanines (G19-G21) or (G20-G22) is involved in the G-tetrad formation (Fig. 4C, models 1 and 2). As shown in Fig. 4B, the binding of NSC311153 (5 equivalents) changes the pattern of $\mathrm{N} 7$ guanine methylation (lane D) in which the guanines (G14-G16) or (G15-G17) is involved in the G-tetrad formation (Fig. 4C, models 1 and 3). The change in the G-quadruplex structure in the presence of this compound clearly suggest that NSC311153 binds with this secondary structure.

Effect of NSC311153 on the promoter activity of RET gene. Since in our previous studies we reported that the G-quadruplex structure formed on the promoter region of 


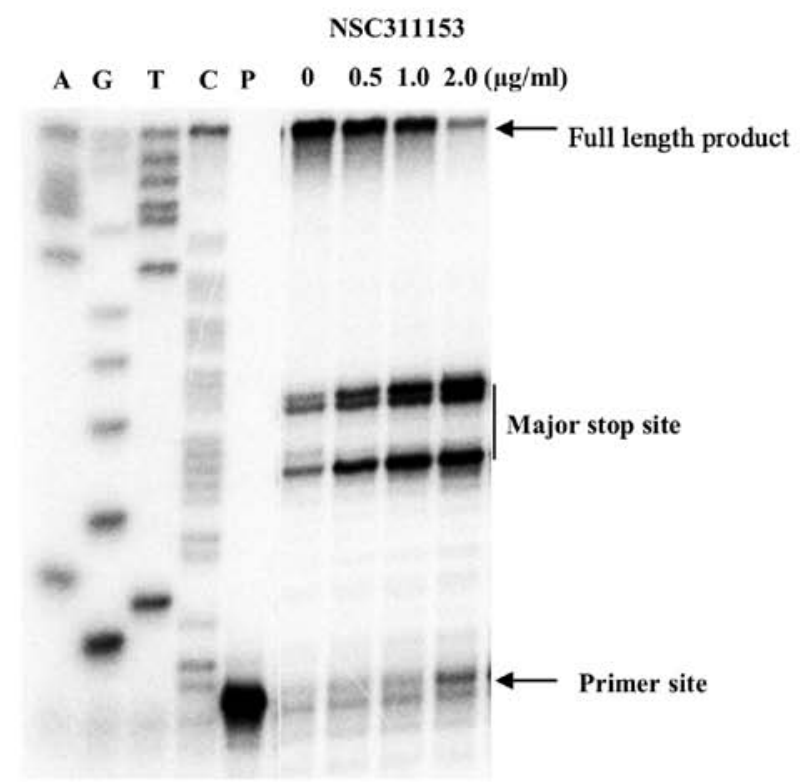

$\mathrm{C}$

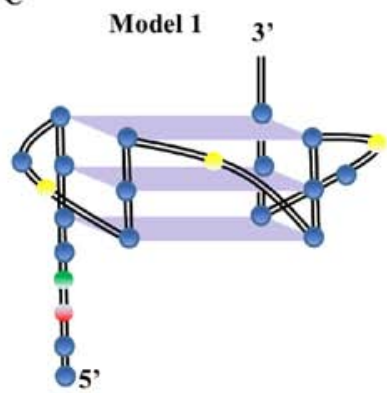

B
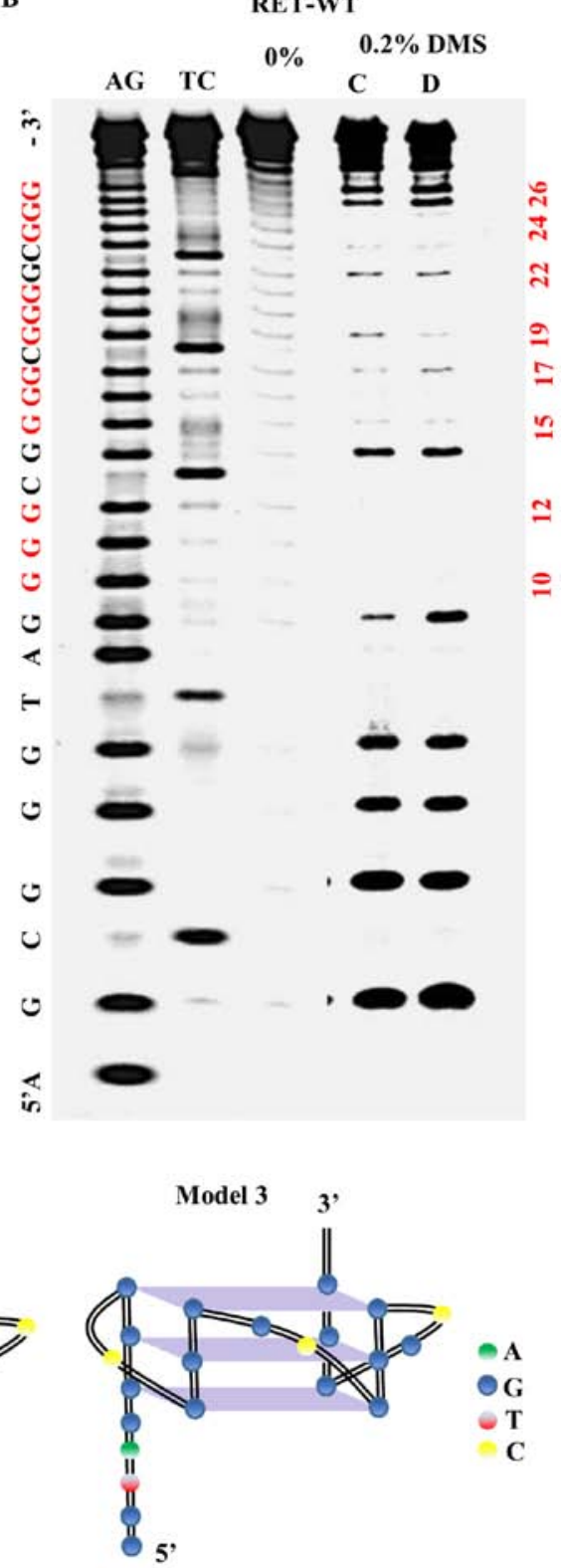

Figure 4. Taq DNA polymerase assay and DMS footprinting to validate the stabilization of RET G-quadruplex by NSC311153. (A) DNA polymerase stop assay at increasing concentrations of NSC311153. Lanes A, G, T and C represent the di-deoxy sequencing reactions with the same template, which serve as the marker to locate the exact stop site. Lane P represents the position of the free primer on the gel. (B) DMS footprinting on the RET-WT G-quadruplex forming sequence in the absence and presence of NSC311153 (5 equivalents) following 0.2\% DMS treatment (lanes C and D, respectively). Purine and pyrimidine sequencing act as single base ladders to identify the protected and cleaved guanines after piperidine treatment (lanes AG and TC, respectively). (C) Schematic models for the parallel G-quadruplexes formed by RET-WT sequence in the absence and presence of NSC311153.

$R E T$ gene acts as transcriptional silencer element, we next examined whether the stabilization of RET G-quadruplex structure by NSC311153 interferes with the transcriptional activation of this gene in TT cell line. As shown in Fig. 5A, NSC311153 decreased the RET mRNA expression by $>50$ and $90 \%$ at a non-toxic concentration of $2.5 \mu \mathrm{g} / \mathrm{ml}$ following the exposure up to 24 and $48 \mathrm{~h}$, respectively. We also utilized the MZ-CRC-1 cell line, which harbors an M918T mutation in the tyrosine kinase domain of the RET protein. Moreover, the RET gene expression in this cell line is regulated by the same promoter region as found in the TT cells, which harbors the G-quadruplex forming motif (44). As shown in Fig. 5B, a dose-dependent decrease in the RET protein expression was observed in the presence of NSC311153 after 48-h incubation.

To determine whether the decrease in RET mRNA expression by NSC311153 is a direct effect of the promoter-specific transcriptional inhibition of this gene, a bioluminescent reporter gene assay was performed using an isogenic cell line HEK293-RET in which the luciferase expression is under the control of the RET promoter region as described in our previous study (23). As shown in Fig. 5C, in the presence of NSC311153 a dose-dependent decrease in the basal luciferase expression was observed in the HEK293-RET cell line following 48-h incubation. To further demonstrate that the mechanism of action of NSC311153 is through stabilizing the G-quadruplex 
A

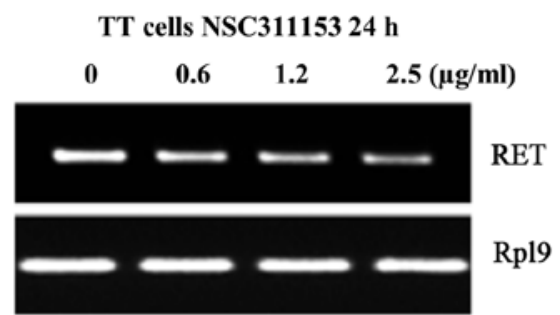

B

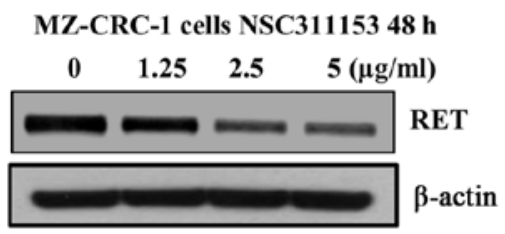

D

TPC1 cells NSC31115348 h

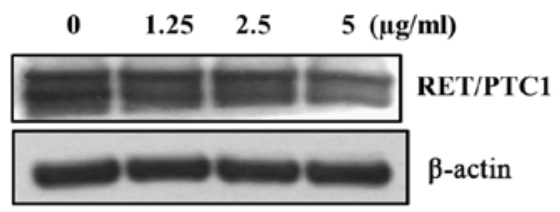

TT cells NSC31115348 h

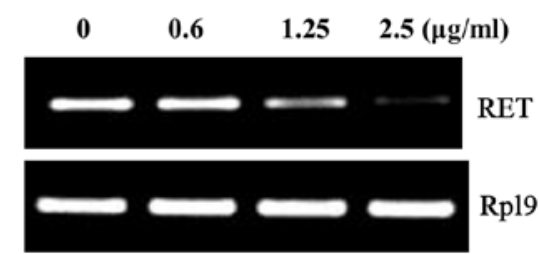

C

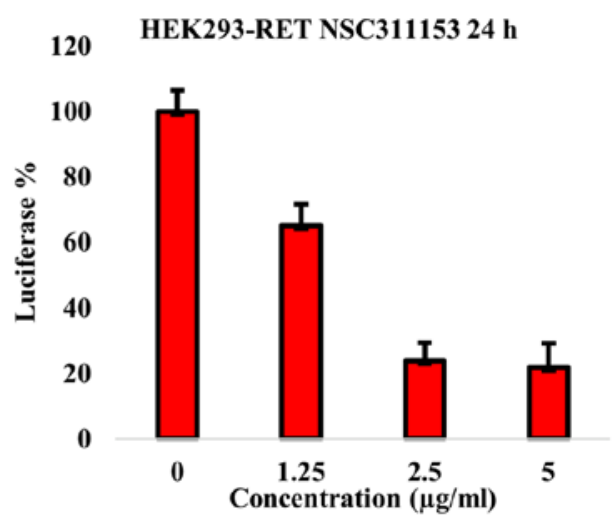

E

TT cells NSC311153 48 h

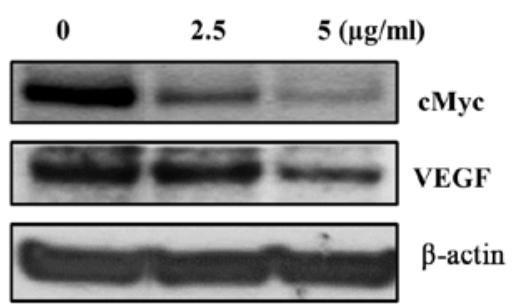

Figure 5. Inhibitory effect of NSC311153 on the promoter activity of RET gene. (A) Effect of NSC311153 on the RET mRNA expression in TT cells after $24-$ and 48-h treatments at various concentrations. (B) Effect of NSC311153 on the RET expression in MZ-CRC-1 cell line was determined by western blotting following 48-h incubation with this compound. (C) Luciferase expression in HEK293-RET cell line following the treatment with NSC311153 up to 24 h. Luciferase activity in cell lysates was measured as relative luminescence units (RLU) and normalized to the total protein content. X-axes and y-axes represent the concentration of NSC311153 and the relative luciferase activity in HEK293-RET cell line, respectively. Data are mean \pm SEM of three different experiments. (D) Effect of NSC311153 on the RET/PTC1 expression in TPC1 cells was determined following 48-h exposure with various concentrations of this compound. (E) Western blot analyses for the expression of c-Myc and VEGF in TT cell line in the presence of different concentrations of NSC311153.

structure present on the RET promoter region, we utilized PTC1 derived TPC1 cells as a control. Chromosomal rearrangement between the $R E T$ kinase domain coding region and the CCD6 gene results in a chimeric RET/PTC1 expression, whose transcriptional activation is controlled by the $C C D 6$ promoter region that lacks the G-quadruplex forming motif (45-49). Notably, NSC311153 did not suppress the RET/ PTC1 expression in this cell line even after 48-h incubation (Fig. 5D). Overall, these data provide clear evidence to support that NSC311153 intervenes in the transcription mechanism of $R E T$ gene by targeting the intracellular G-quadruplex structure formed on its promoter region.

Cellular effects mediated by NSC311153 due to RET downregulation. The oncogenic RET activation is mainly involved in mediating the cell proliferation and survival and hence the effect of NSC311153 on the viability of TT cell line was determined using the MTS assay. As shown in Fig. 6A the proliferation of the TT cells decreased with increasing concentrations of NSC311153 and the $\mathrm{IC}_{50}$ was found to be $\sim 2.5 \mu \mathrm{g} / \mathrm{ml}$ after 96-h exposure. The TPCl cell line in which the RET/PTC1 expression was not inhibited by NSC311153 was less sensitive to this compound and the $\mathrm{IC}_{50}$ was 10 -fold more than the TT cells (Fig. 6A). This clearly shows that the inhibition of cell growth by NSC311153 is mediated through the downregulation of the RET gene. To further determine whether the anti-proliferative effect of NSC311153 is cancer cell-specific, we included a normal thyroid cell line, Nthy-ori-3-1 in the present study. Based on the MTS data, the $\mathrm{IC}_{50}$ of NSC311153 in the Nthy-ori-3-1 cell line was estimated to be $10 \mu \mathrm{g} / \mathrm{ml}$ (Fig. 6A), which is 4-fold higher than that of TT cells, suggesting that this compound is selectively sensitive to the mutant RET driven thyroid cancer.

To further characterize the mechanism through which NSC311153 suppresses the TT cell proliferation, we investigated whether this compound inhibits the RET mediated 
A

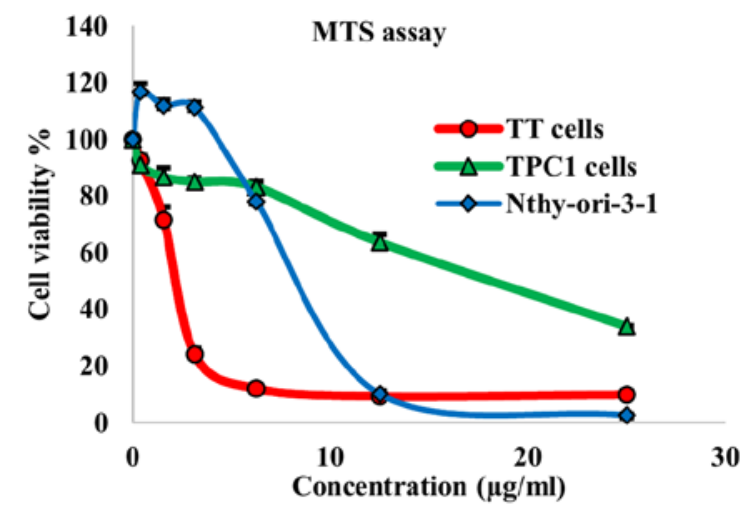

C

TPC1 cells NSC311153 $48 \mathrm{~h}$

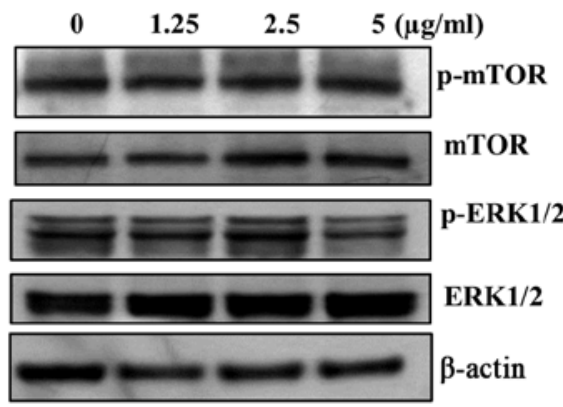

E

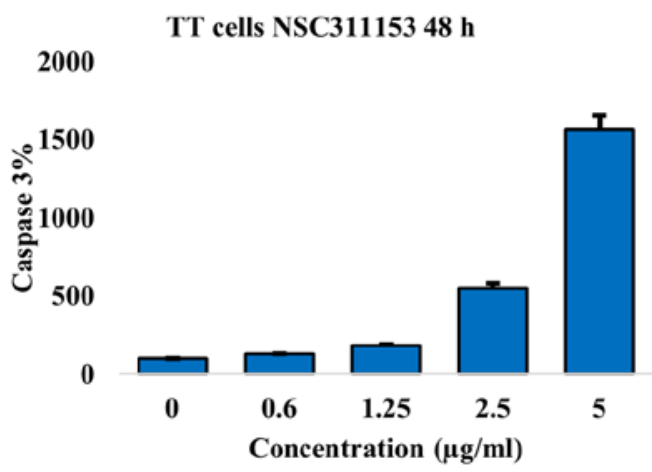

B

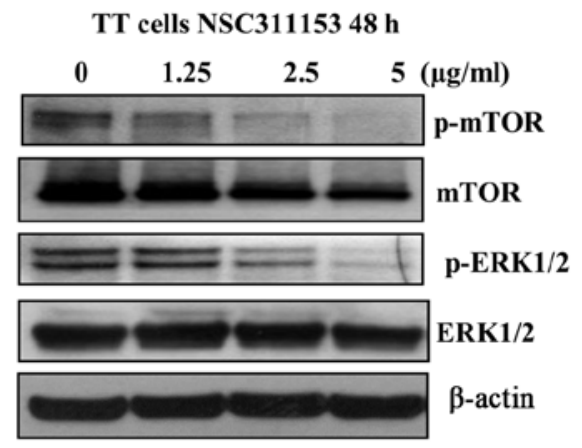

D

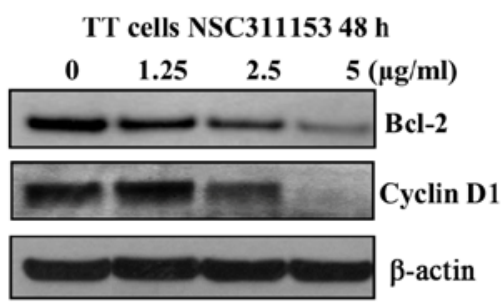

$\mathbf{F}$

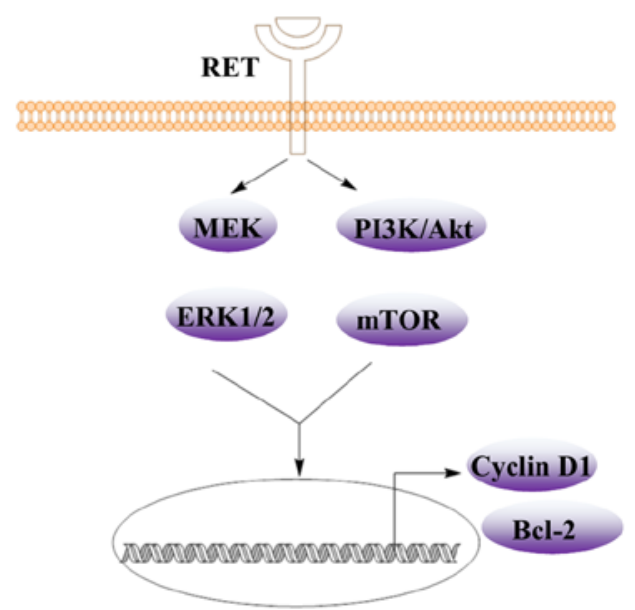

Figure 6. Cellular effects mediated by RET downregulation. (A) MTS assay for TT, TPC1 and Nthy-ori-3-1 cells treated with an increasing concentration of NSC311153 for $96 \mathrm{~h}$ to determine the cell viability. $\mathrm{x}$-axes and y-axes represent the concentration of NSC311153 and the relative cell viability, respectively. Data are mean \pm SEM of three separate experiments. (B) The phosphorylation status of mTOR and ERK1/2 were determined in TT and TPC1 cells following the exposure with different concentrations of NSC311153. (C) Western blot analysis to determine the effect of NSC311153 on the phosphorylation of ERK1/2 and mTOR in TPC1 cells. (D) The Bcl-2 and cyclin D1 protein expressions in TT cells were determined by western blotting. (E) Caspase-3 activity was determined in TT cells in the presence of NSC311153. x-axes and y-axes represent the concentration of NSC311153 and the relative caspase-3 activity respectively. Data are mean \pm SEM of three separate experiments. (F) Schematic representation of the signaling pathways that are regulated by oncogenic activation of RET kinase (10).

downstream signal transduction pathways. Previous studies have revealed that RET activates the Raf/MEK and PI3K/Akt downstream signaling pathways, which in turn phosphorylate and activate ERK1/2 and mammalian target of rapamycin (mTOR) proteins, respectively (10-12). As shown in Fig. 6B, the phosphorylation status of ERK1/2 and mTOR were decreased in a dose-dependent manner following the exposure of TT cells in the presence of NSC311153 up to $48 \mathrm{~h}$. However, in TPC1 cells the phosphorylation levels of these proteins were not altered by NSC311153 (Fig. 6C). These data clearly suggest that the inhibitory effect of NSC311153 on this pathway is a consequence of RET downregulation.

The Raf/MEK/ERK and PI3K/Akt/mTOR pathways are known to promote cancer cell survival through the activation of cyclin D1 and Bcl-2, which are involved in enhancing cellcycle progression and inhibiting the apoptosis mechanism, respectively (50-52). As shown in Fig. 6D, NSC311153 also decreased the expression of cyclin D1 and Bcl-2 in TT cells in a concentration-dependent manner. Furthermore, the downregulation of $\mathrm{Bcl}-2$ by NSC311153 is further accompanied by 

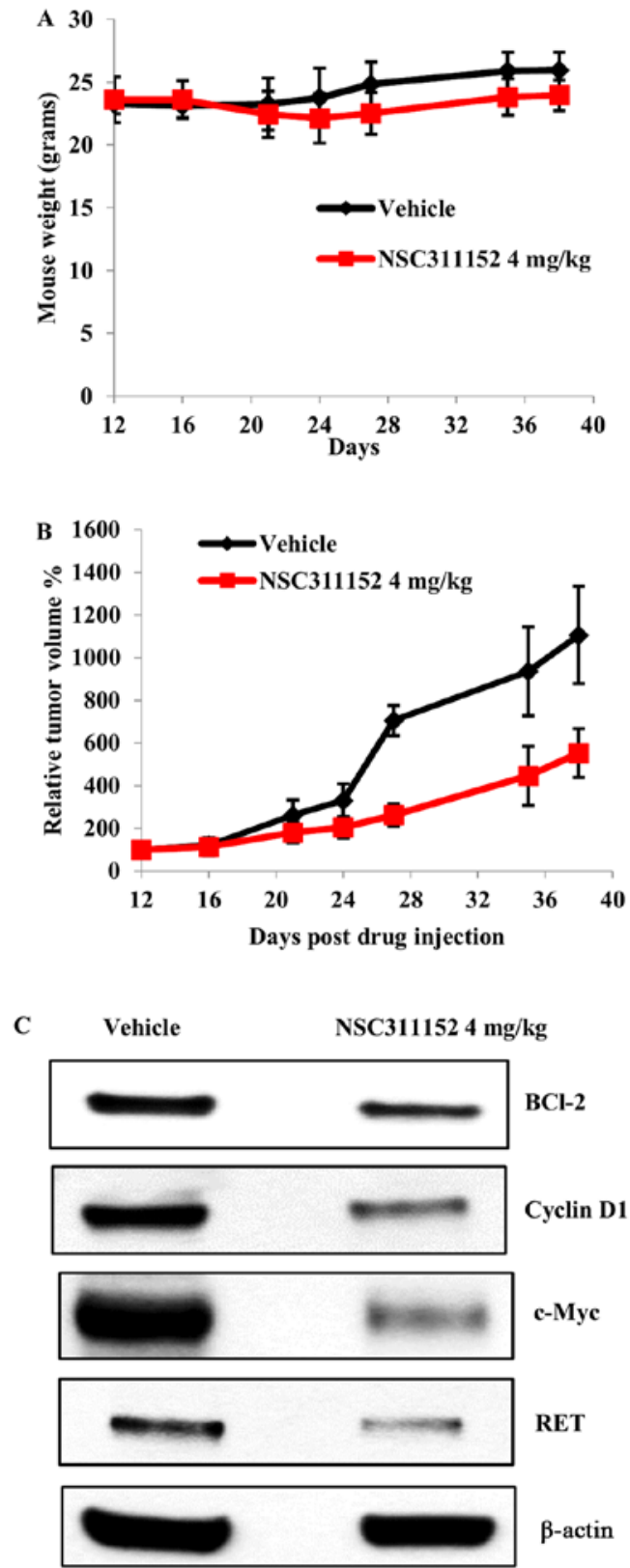

Figure 7. Effect of ellipticine derivative, NSC311152 on the MTC tumor growth in vivo. (A) Average weight of mice in vehicle treated group and NSC311152 $(4 \mathrm{mg} / \mathrm{kg})$ treated group. $\mathrm{x}$ - and $y$-axes represent the number of days after drug administration and the average mouse weight, respectively. (B) MTC tumor growth curves of the vehicle treated group and NSC311152 $(4 \mathrm{mg} / \mathrm{kg}$ ) treated group. $\mathrm{x}$-axes and $\mathrm{y}$-axes represent the number of days after drug administration and the average tumor volume, respectively. Data are mean \pm SEM of 6 different mice. (C) Western blot analysis to determine the expression of RET, cMyc, Bcl-2 and cyclin D1 on the tumor tissues extracted from the drug treated and vehicle treated mice.

the increase in the caspase- 3 activity, which is also a known indicator of apoptosis (Fig. 6E).

In vivo antitumor activity of ellipticine derivative. In the final step of the present study, we evaluated the in vivo effect of the ellipticine derivative on the tumor growth of MTC xenografts through subcutaneous injection of the TT cells into SCID mice. Although NSC311153 showed potential antiproliferative effects in TT cells in vitro, the poor solubility of this compound hindered its in vivo antitumor examination.
However, a previous study reported that a water soluble ellipticine analog, NSC311152 (datelliptium) was well tolerated in different cancer patients in a phase-I clinical trial (53). As shown in Fig. 1, the structure of NSC311152 is very similar to NSC311153 with the presence of a diethylaminoethyl-moiety at position $\mathrm{N}-2$ that improves the solubility of this compound compared to that of NSC311153. Based on our preliminary data, the inhibitory effect of NSC311152 on RET expression and its $\mathrm{IC}_{50}$ value is the same as that of NSC311153, suggesting that the slight structural modification does not alter the efficacy of this compound. Hence, we decided to pursue with NSC311152 to test the in vivo antitumor activity. Dosing regimen and treatment schedules were determined based on our preliminary dose optimization studies. Upon systemic administration via i.p, NSC311152 (4 mg/kg) was well tolerated without any significant decrease in the average body weight (Fig. 7A). As shown in Fig. 7B, $60 \%$ inhibition of the tumor growth was observed in mice treated with NSC311152 compared to the vehicle treated group. To further validate whether the inhibition of tumor growth by NSC311152 in vivo is mediated through target specific effect, we determined the RET expression in tumor tissues of vehicle- and NSC311152treated mice using western blotting. As shown in Fig. 7C, the RET protein expression was decreased in the presence of NSC311152 compared to that of vehicle. Furthermore, NSC311152 reduced the expression of other proteins such as c-Myc, Bcl-2 and cyclin D1 that contribute to cell proliferation, which is in accordance with the in vitro studies. Overall, these data suggest that NSC311152 possesses potent in vivo antitumor activity through RET downregulation.

\section{Discussion}

RET was previously described as a regulator of several intracellular signaling events that contribute to the well-recognized biological processes such as cell survival, proliferation, migration and invasion (54). Hence, it is easy to understand why the constitutive activation of this protein due to point mutations in the functional domains is mainly involved in the progression of MTC. The clinical responses to standard chemotherapy and radiation therapy in patients with MTC have been shown to be less effective thereby representing MTC as a promising disease for the field of targeted drug therapy (55-57). Therapeutic approaches that target the RET kinase activity using small-molecule kinase inhibitors such as vandetanib and cabozantinib have proved to be clinically valuable in MTC $(58,59)$. However, these kinase inhibitors possess potential inhibitory effects on other tyrosine-kinase receptors like VEGFR, EGFR, MET and hence the development of a specific inhibitor for RET still remains challenging $(60,61)$. Moreover, a previous study demonstrated that the RET kinase carrying a substitution mutation of V804 to a bulky hydrophobic leucine or methionine amino-acids at the gatekeeper region in ATP binding pocket confers resistance to the kinase inhibitors (62). Hence, these gatekeeper mutations will likely emerge as one of the obstacles in the long-term use of vandetanib and cabozantinib in the treatment of patients with advanced MTC.

Another possible approach for the treatment of RET associated MTC involves the use of small interfering RNAs (siRNAs) to silence the $R E T$ gene expression. In a previous 
investigation the transfection of TT cell line with RET siRNA exerted anti-proliferative effects on this cell line and also inhibited the growth of tumor xenografts in vivo (63). However, the development of siRNAs as drug-like molecules possesses several pitfalls that mainly include difficulty in delivering these molecules into target cells and their extracellular instability $(64,65)$. The siRNAs are large and negatively charged molecules that greatly affect their permeability into plasma membrane and prevent intracellular accumulation at their site of action. Furthermore, siRNAs are highly susceptible to degradation by many extracellular enzymes that undermine the clinical implications of these molecules (65). To overcome these challenges, this study mainly focuses in targeting the transcription of the RET proto-oncogene using small molecules.

In our previous studies we have clearly demonstrated that the polypurine/polypyrimidine tract within the RET gene promoter region has a propensity to undergo strand separation that leads to conformational transition between duplex DNA and G-quadruplex structures $(28,29)$. Moreover, we have also shown that the stabilization of these structures using small molecules emerged as potential transcriptional repressors of $R E T$ gene $(23,24)$. The present study is based on a previous report, which revealed the interaction of a putative anticancer agent, ellipticine with the G-quadruplex structure formed by the human telomeric sequence (37). However, due to the adverse cytotoxic effects of ellipticine, we investigated the interaction of other ellipticine analogs with the RET G-quadruplex structure using in vitro biochemical assays. Notably, we identified an ellipticine derivative, NSC311153, which has a 2-piperidin1-ylethyl moiety at position $\mathrm{N}-2$ as a potent stabilizer of the RET G-quadruplex structure. The structure activity relationship (SAR) analysis clearly revealed that the presence of 1-ethylpiperidine at the N-2 position improves the binding of NSC311153 with the RET G-quadruplex and also significantly decreases the cellular toxicity compared to its parent molecule, ellipticine. The stabilization of the G-quadruplex structure by NSC311153 also exerted inhibitory effects on the RET promoter activity, which was confirmed using bioluminescent reporter assay in which the luciferase gene expression is driven by the RET promoter region. This compound further inhibited the RET mRNA and protein expression in TT cells, which harbor a MEN2A-type mutation. The transcriptional inhibitory effect of NSC31153 on other oncogenes like VEGF and $c-M Y C$ that also harbor the G-quadruplex forming sequences on their promoter regions was also investigated $(66,67)$. As shown in Fig. 5E, the c-MYC expression showed a dose-dependent decrease in the presence of NSC311153, which is consistent with a previous study (37). Moreover, the VEGF expression was also partially inhibited by this compound suggesting that the G-quadruplex structure could be a potential intra-cellular target for NSC311153 (Fig. 5E).

In the present study, we also addressed that NSC311153 inhibited the proliferation of TT cells through the downregulation of RET expression. The oncogenic RET activation promotes cell growth and survival by transducing a cascade of intracellular signaling pathways. In a previous study by Drosten et al (10) the RET associated downstream signaling pathways that are required for tumor maintenance and progression were well characterized in the TT cell line. In their study, they used adenoviral vector expressing the dominant negative truncated RET protein, which lacks the entire intracellular tyrosine kinase domain to disrupt the phosphorylation and activation of RET protein in TT cells. This resulted in the downregulation of Raf/MEK/ERK and PI3K/Akt/mTOR pathways suggesting that these two pathways are mainly involved in RET mediated transformation (10). Consistent with this study, we also observed that the suppression of RET expression by NSC311153 inhibited the phosphorylation of ERK and mTOR and further decreased the expression of cyclin D1 and $\mathrm{Bcl}-2$ that are tightly regulated by $\mathrm{Raf} / \mathrm{MEK} / \mathrm{ERK}$ and PI3K/Akt/mTOR pathways (Fig. 6F). Notably, we also observed that the normal thyroid cells, Nthy-ori-3-1 showed significant resistance to NSC311153 with an $\mathrm{IC}_{50}$ of $10 \mu \mathrm{g} / \mathrm{ml}$ suggesting that this compound is more selective to mutant RET driven thyroid cancer.

To validate the drug-target selectivity, we utilized TPC1 cell line in this study, which is more robust and direct in demonstrating the RET G4-targeted activity of NSC311153. The chromosomal rearrangement between the RET tyrosine kinase domain coding region with the $5^{\prime}$ terminal region of the coiled-coil domain containing gene $6(C C D 6)$ at chromosome $10 q 11.2$ is a common genetic alteration identified in TPC1 cell line (46). This results in a chimeric fusion protein RET/PTC1, which is capable of ligand independent homodimerization due to the dimerization domain present in the CCD6 gene thereby resulting in the constitutive activation of this protein (47). Due to chromosomal inversion the transcription of the RET/PTC1 gene is regulated by the CCD6 gene promoter region in TPC1 cells, which does not have the GC box region and thus is unable to form the G-quadruplex structure (49). In the present study, the RET/PTC1 expression was not decreased in the presence of NSC311153, suggesting that the presence of G-quadruplex structure on the promoter region of $R E T$ gene is essential to mediate the inhibitory effect of this compound. Based on the MTS data, the $\mathrm{IC}_{50}$ of this compound in TPC1 cell line was 10-fold higher than that in TT cells, which clearly suggest that the anti-proliferative effect of NSC311153 is specifically mediated through RET downregulation.

In the present study, we also reported the in vivo antitumor activity of a water soluble NSC311153 analog, NSC311152 (datelliptium) in MTC xenograft mouse models. A phase I clinical study has been previously carried out using NSC311152 in patients with metastatic breast, ovarian, gastric and colorectal cancers (53). Based on that study, the maximum tolerated dose in humans was determined to be $9 \mathrm{mg} / \mathrm{kg}$ with minimal side-effects such as nausea, mild diarrhea, dry mouth and fatigue (53). Since NSC311152 has been investigated in clinical trial, repurposing this compound as a potent anticancer agent for MTC therapy has better advantages in terms of safety and other pharmacokinetic parameters compared to NSC311153. Moreover, the structural modification in NSC311152 did not affect the potency of this molecule in downregulating the RET expression in vitro. Hence, in this study we attempted to examine the in vivo effects of NSC31112.

Overall, the present study supports the notion that the G-quadruplex mediated RET transcriptional inhibition may be a valid therapeutic approach for the treatment of advanced and metastatic MTC. The identified RET transcriptional inhibitors could also be used in combination with other clinically avail- 
able kinase inhibitors to improve their therapeutic efficacy in MTC patients.

\section{Acknowledgements}

We thank the U.S. NCI/DTP Open Chemical Repository for providing the chemicals used in the present study.

\section{References}

1. Takahashi M and Cooper GM: ret transforming gene encodes a fusion protein homologous to tyrosine kinases. Mol Cell Biol 7: 1378-1385, 1987.

2. Patel A, Harker N, Moreira-Santos L, Ferreira M, Alden K, Timmis J, Foster K, Garefalaki A, Pachnis P, Andrews P, et al: Differential RET signaling pathways drive development of the enteric lymphoid and nervous systems. Sci Signal 5: ra55, 2012.

3. Takahashi M, Buma Y, Iwamoto T, Inaguma Y, Ikeda H and Hiai $\mathrm{H}$ : Cloning and expression of the ret proto-oncogene encoding a tyrosine kinase with two potential transmembrane domains. Oncogene3: 571-578, 1988.

4. Takahashi M, Buma Y and Hiai H: Isolation of ret proto-oncogene cDNA with an amino-terminal signal sequence. Oncogene 4 805-806, 1989.

5. Anders J, Kjar S and Ibáñez CF: Molecular modeling of the extracellular domain of the RET receptor tyrosine kinase reveals multiple cadherin-like domains and a calcium-binding site. J Biol Chem 276: 35808-35817, 2001.

6. Durbec P, Marcos-Gutierrez CV, Kilkenny C, Grigoriou M, Wartiowaara K, Suvanto P, Smith D, Ponder B, Costantini F, Saarma M, et al: GDNF signalling through the Ret receptor tyrosine kinase. Nature 381: 789-793, 1996.

7. Trupp M, Arenas E, Fainzilber M, Nilsson AS, Sieber BA, Grigoriou M, Kilkenny C, Salazar-Grueso E, Pachnis V, Arumäe U, et al: Functional receptor for GDNF encoded by the c-ret proto-oncogene. Nature 381: 785-789, 1996.

8. Cosma MP, Cardone M, Carlomagno F and Colantuoni V: Mutations in the extracellular domain cause RET loss of function by a dominant negative mechanism. Mol Cell Biol 18: 3321-3329, 1998.

9. Iwashita T, Asai N, Murakami H, Matsuyama M and Takahashi M: Identification of tyrosine residues that are essential for transforming activity of the ret proto-oncogene with MEN2A or MEN2B mutation. Oncogene 12: 481-487, 1996.

10. Drosten M, Hilken G, Böckmann M, Rödicker F, Mise N, Cranston AN, Dahmen U, Ponder BA and Pützer BM: Role of MEN2A-derived RET in maintenance and proliferation of medullary thyroid carcinoma. J Natl Cancer Inst 96: 1231-1239, 2004.

11. Pitt SC and Chen H: The phosphatidylinositol 3-kinase/akt signaling pathway in medullary thyroid cancer. Surgery 144 : 721-724, 2008

12. Melillo RM, Santoro M, Ong SH, Billaud M, Fusco A Hadari YR, Schlessinger J and Lax I: Docking protein FRS2 links the protein tyrosine kinase RET and its oncogenic forms with the mitogen-activated protein kinase signaling cascade. Mo Cell Biol 21: 4177-4187, 2001.

13. Chen Z, Qi X, Fei J, Yu X, Zhao Y, Zhao J, Jin H, Wang J, Ying R and Zhang $\mathrm{X}$ : Multiple endocrine neoplasia type $2 \mathrm{~A}$ caused by a p.C618R RET proto-oncogene mutation in a Chinese pedigree. Zhonghua Yi Xue Yi Chuan Xue Za Zhi 31: 348-351, 2014 (In Chinese).

14. Lodish MB and Stratakis CA: RET oncogene in MEN2, MEN2B, MTC and other forms of thyroid cancer. Expert Rev Anticancer Ther 8: 625-632, 2008 .

15. Mulligan LM, Kwok JB, Healey CS, Elsdon MJ, Eng C, Gardner E, Love DR, Mole SE, Moore JK, Papi L, et al: Germ-line mutations of the RET proto-oncogene in multiple endocrine neoplasia type 2A. Nature 363: 458-460, 1993.

16. Asai N, Iwashita T, Matsuyama M and Takahashi M: Mechanism of activation of the ret proto-oncogene by multiple endocrine neoplasia 2A mutations. Mol Cell Biol 15: 1613-1619, 1995.

17. Aboelnaga EM and Ahmed RA: Difference between papillary and follicular thyroid carcinoma outcomes: An experience from Egyptian institution. Cancer Biol Med 12: 53-59, 2015.

18. Milan SA, Sosa JA and Roman SA: Current management of medullary thyroid cancer. Minerva Chir 65: 27-37, 2010.
19. Cabanillas ME, Hu MI, Jimenez C, Grubbs EG and Cote GJ: Treating medullary thyroid cancer in the age of targeted therapy. Int J Endocr Oncol 1: 203-216, 2014.

20. de Groot JW, Links TP, Plukker JT, Lips CJ and Hofstra RM: RET as a diagnostic and therapeutic target in sporadic and hereditary endocrine tumors. Endocr Rev 27: 535-560, 2006.

21. Plaza-Menacho I, Burzynski GM, de Groot JW, Eggen BJ and Hofstra RM: Current concepts in RET-related genetics, signaling and therapeutics. Trends Genet 22: 627-636, 2006.

22. Wells SA Jr and Santoro M: Targeting the RET pathway in thyroid cancer. Clin Cancer Res 15: 7119-7123, 2009.

23. Shin YJ, Kumarasamy V, Camacho D and Sun D: Involvement of G-quadruplex structures in regulation of human RET gene expression by small molecules in human medullary thyroid carcinoma TT cells. Oncogene 34: 1292-1299, 2015.

24. Kumarasamy VM, Shin YJ, White J and Sun D: Selective repression of RET proto-oncogene in medullary thyroid carcinoma by a natural alkaloid berberine. BMC Cancer 15: 599 , 2015.

25. Andrew SD, Capes-Davis A, Delhanty PJ, Marsh DJ, Mulligan LM and Robinson BG: Transcriptional repression of the RET proto-oncogene by a mitogen activated protein kinasedependent signalling pathway. Gene 298: 9-19, 2002.

26. Bachetti T, Borghini S, Ravazzolo R and Ceccherini I: An in vitro approach to test the possible role of candidate factors in the transcriptional regulation of the RET proto-oncogene. Gene Expr 12: 137-149, 2005.

27. Andrew SD, Delhanty PJ, Mulligan LM and Robinson BG: Sp1 and $\mathrm{Sp} 3$ transactivate the RET proto-oncogene promoter. Gene 256: 283-291, 2000.

28. Guo K, Pourpak A, Beetz-Rogers K, Gokhale V, Sun D and Hurley LH: Formation of pseudosymmetrical G-quadruplex and i-motif structures in the proximal promoter region of the RET oncogene. J Am Chem Soc 129: 10220-10228, 2007.

29. Sun D, Guo K, Rusche JJ and Hurley LH: Facilitation of a structural transition in the polypurine/polypyrimidine tract within the proximal promoter region of the human VEGF gene by the presence of potassium and G-quadruplex-interactive agents. Nucleic Acids Res 33: 6070-6080, 2005.

30. Sun D and Hurley LH: The importance of negative superhelicity in inducing the formation of $\mathrm{G}$-quadruplex and i-motif structures in the c-Myc promoter: Implications for drug targeting and control of gene expression. J Med Chem 52: 2863-2874, 2009.

31. Parkinson GN, Lee MP and Neidle S: Crystal structure of parallel quadruplexes from human telomeric DNA. Nature 417: 876-880, 2002.

32. Burge S, Parkinson GN, Hazel P, Todd AK and Neidle S: Quadruplex DNA: Sequence, topology and structure. Nucleic Acids Res 34: 5402-5415, 2006.

33. Paoletti C, Le Pecq JB, Dat-Xuong N, Juret P, Garnier H, Amiel JL and Rouesse J: Antitumor activity, pharmacology, and toxicity of ellipticines, ellipticinium, and 9-hydroxy derivatives: Preliminary clinical trials of 2-methyl-9-hydroxy ellipticinium (NSC 264-137). Recent Results Cancer Res 74: 107-123, 1980.

34. Rouëssé J, Spielmann M, Turpin F, Le Chevalier T, Azab M and Mondésir JM: Phase II study of elliptinium acetate salvage treatment of advanced breast cancer. Eur J Cancer 29A: 856-859, 1993.

35. Fossé P, René B, Charra M,Paoletti C and Saucier JM: Stimulation of topoisomerase II-mediated DNA cleavage by ellipticine derivatives: Structure-activity relationship. Mol Pharmacol 42: 590-595, 1992.

36. Barrett JF, Gootz TD, McGuirk PR, Farrell CA and Sokolowski SA: Use of in vitro topoisomerase II assays for studying quinolone antibacterial agents. Antimicrob Agents Chemother 33: 1697-1703, 1989.

37. Ghosh S, Kar A, Chowdhury S and Dasgupta D: Ellipticine binds to a human telomere sequence: An additional mode of action as a putative anticancer agent? Biochemistry 52: 4127-4137, 2013.

38. Brown RV, Danford FL, Gokhale V, Hurley LH and Brooks TA: Demonstration that drug-targeted down-regulation of MYC in non-Hodgkins lymphoma is directly mediated through the promoter G-quadruplex. J Biol Chem 286: 41018-41027, 2011.

39. Han H, Hurley LH and Salazar M: A DNA polymerase stop assay for G-quadruplex-interactive compounds. Nucleic Acids Res 27: 537-542, 1999.

40. Sun D and Hurley LH: Biochemical techniques for the characterization of G-quadruplex structures: EMSA, DMS footprinting, and DNA polymerase stop assay. Methods Mol Biol 608: 65-79, 2010. 
41. Riss TL, Moravec RA, Niles AL, Duellman S, Benink HA, Worzella TJ and Minor L: Cell Viability Assays. In: Assay Guidance Manual. Sittampalam GS, Coussens NP, Nelson H, et al (eds). Bethesda (MD), 2004, vol. 10.1590/S180683242009000300006 .

42. Gray DM, Gray CW, Mou TC and Wen JD: CD of single-stranded, double-stranded, and G-quartet nucleic acids in complexes with a single-stranded DNA-binding protein. Enantiomer 7: 49-58, 2002.

43. González V, Guo K, Hurley L and Sun D: Identification and characterization of nucleolin as a c-myc G-quadruplex-binding protein. J Biol Chem 284: 23622-23635, 2009.

44. Zhu W, Hai T, Ye L and Cote GJ: Medullary thyroid carcinoma cell lines contain a self-renewing $\mathrm{CD} 133^{+}$population that is dependent on ret proto-oncogene activity. J Clin Endocrinol Metab 95: 439-444, 2010

45. Grieco M, Santoro M, Berlingieri MT, Melillo RM, Donghi R Bongarzone I, Pierotti MA, Della Porta G, Fusco A and Vecchio G: PTC is a novel rearranged form of the ret protooncogene and is frequently detected in vivo in human thyroid papillary carcinomas. Cell 60: 557-563, 1990.

46. Fusco A, Grieco M, Santoro M, Berlingieri MT, Pilotti S, Pierotti MA, Della Porta G and Vecchio G: A new oncogene in human thyroid papillary carcinomas and their lymph-nodal metastases. Nature 328: 170-172, 1987.

47. Nikiforov YE: RET/PTC rearrangement in thyroid tumors. Endocr Pathol Spring 13: 3-16, 2002.

48. Schweppe RE: Thyroid cancer cell line misidentification: An update. J Clin Endocrinol Metab 98: 956-957, 2013.

49. Tong Q, Li Y, Smanik PA, Fithian LJ, Xing S, Mazzaferri EL and Jhiang SM: Characterization of the promoter region and oligomerization domain of H4 (D10S170), a gene frequently rearranged with the ret proto-oncogene. Oncogene 10: 1781-1787, 1995.

50. Baldin V, Lukas J, Marcote MJ, Pagano M and Draetta G: Cyclin D1 is a nuclear protein required for cell cycle progression in G1. Genes Dev 7: 812-821, 1993.

51. Tsujimoto Y: Role of Bcl-2 family proteins in apoptosis: Apoptosomes or mitochondria? Genes Cells 3: 697-707, 1998.

52. McCubrey JA, Steelman LS, Chappell WH, Abrams SL, Wong EW, Chang F, Lehmann B, Terrian DM, Milella M, Tafuri A, et al: Roles of the Raf/MEK/ERK pathway in cell growth, malignant transformation and drug resistance. Biochim Biophys Acta 1773: 1263-1284, 2007.

53. Khayat D, Borel C, Azab M, Paraisot D, Malaurie E, Bouloux C and Weil M: Phase I study of Datelliptium chloride, hydrochloride given by 24-h continuous intravenous infusion. Cancer Chemother Pharmacol 30: 226-228, 1992.

54. Jain S: The many faces of RET dysfunction in kidney. Organogenesis 5: 177-190, 2009.
55. Matuszczyk A, Petersenn S, Bockisch A, Gorges R, Sheu SY, Veit P and Mann K: Chemotherapy with doxorubicin in progressive medullary and thyroid carcinoma of the follicular epithelium. Horm Metab Res 40: 210-213, 2008.

56. Terezakis SA and Lee NY: The role of radiation therapy in the treatment of medullary thyroid cancer. J Natl Compr Canc Netw 8: 532-540, quiz 541, 2010.

57. Ferrari SM, Fallahi P, Politti U, Materazzi G, Baldini E, Ulisse S, Miccoli P and Antonelli A: Molecular targeted therapies of aggressive thyroid cancer. Front Endocrinol (Lausanne) 6: 176, 2015.

58. Wells SA Jr, Robinson BG, Gagel RF, Dralle H, Fagin JA, Santoro M, Baudin E, Elisei R, Jarzab B, Vasselli JR, et al: Vandetanib in patients with locally advanced or metastatic medullary thyroid cancer: A randomized, double-blind phase III trial. J Clin Oncol 30: 134-141, 2012.

59. Elisei R, Schlumberger MJ, Müller SP, Schöffski P, Brose MS, Shah MH, Licitra L, Jarzab B, Medvedev V, Kreissl MC, et al: Cabozantinib in progressive medullary thyroid cancer. J Clin Oncol 31: 3639-3646, 2013

60. Chau NG and Haddad RI: Vandetanib for the treatment of medullary thyroid cancer. Clin Cancer Res 19: 524-529, 2013.

61. Yakes FM, Chen J, Tan J, Yamaguchi K, Shi Y, Yu P, Qian F, Chu F, Bentzien F, Cancilla B, et al: Cabozantinib (XL184), a novel MET and VEGFR2 inhibitor, simultaneously suppresses metastasis, angiogenesis, and tumor growth. Mol Cancer Ther 10: 2298-2308, 2011.

62. Carlomagno F, Guida T, Anaganti S, Vecchio G, Fusco A, Ryan AJ, Billaud M and Santoro M: Disease associated mutations at valine 804 in the RET receptor tyrosine kinase confer resistance to selective kinase inhibitors. Oncogene 23: 6056-6063, 2004.

63. Koga K, Hattori Y, Komori M, Narishima R, Yamasaki M Hakoshima M, Fukui T and Maitani Y: Combination of RET siRNA and irinotecan inhibited the growth of medullary thyroid carcinoma TT cells and xenografts via apoptosis. Cancer Sci 101: 941-947, 2010.

64. Agrawal N,Dasaradhi PV,Mohmmed A,MalhotraP,BhatnagarRK and Mukherjee SK: RNA interference: Biology, mechanism, and applications. Microbiol Mol Biol Rev 67: 657-685, 2003.

65. Gavrilov K and Saltzman WM: Therapeutic siRNA: Principles, challenges, and strategies. Yale J Biol Med 85: 187-200, 2012.

66. Sun D, Guo K and Shin YJ: Evidence of the formation of G-quadruplex structures in the promoter region of the human vascular endothelial growth factor gene. Nucleic Acids Res 39: 1256-1265, 2011

67. Siddiqui-Jain A, Grand CL, Bearss DJ and Hurley LH: Direct evidence for a $\mathrm{G}$-quadruplex in a promoter region and its targeting with a small molecule to repress c-MYC transcription. Proc Natl Acad Sci USA 99: 11593-11598, 2002. 